\title{
PODER LEGISLATIVO E MULHERES EM ARAUCÁRIA $(1890-2016)^{1}$
}

\author{
Adriane dos Santos Tavella Ferrari² \\ Ana Crhistina Vanali ${ }^{3}$
}

- Enviado em 15/04/2016

- Aprovado em 20/05/2016

\begin{abstract}
RESUMO
Este artigo tem por objetivo analisar a participação política das mulheres na Câmara Municipal de Araucária, município da região metropolitana de Curitiba/PR entre os anos de 1890 a 2016. Para tanto, um banco de dados das candidatas eleitas foi construído e, com ele, foi possível apresentar um balanço da participação das mulheres nas eleições municipais, analisar o perfil das vereadoras a partir de dimensões sociais e econômicas, tais como idade, estado civil, escolaridade, profissão e filiação partidária. Os resultados marcam uma participação feminina muito baixa se comparada com a presença masculina. Em que pese certa abertura e incentivo no sentido de maior participação das mulheres na vida político-partidária, como estabelece a lei de cotas, essa participação está muito aquém do seu contingente populacional, como revelam os dados sobre a participação feminina no poder legislativo local de Araucária.
\end{abstract}

Palavras-chave: Mulheres na política. Política e gênero. Câmara Municipal Araucária.

\section{INTRODUÇÃO}

Nos séculos XVI e XVII a região onde hoje é localizada Araucária era conhecida como Tindiquera e era habitada principalmente ela etnia Guarani. A área onde hoje está instalado o município de Araucária foi uma doação de sesmaria, em 1668, do Capitão Mor Gabriel de Lara a Domingos Rodrigues da Cunha e seus filhos na região de conhecida como Tindiqüera. No final do século XVII, eram proprietários de terras na região o Alferes Gaspar Carrasco do Reis, Luiz da

\footnotetext{
${ }^{1}$ Uma versão preliminar desse trabalho foi apresentada no GT1: INSTITUIÇÕES E PODER: PARENTESCOS E GENEALOGIAS do VII Seminário Nacional de Sociologia e Política da UFPR realizado de 11 a 13 de maio de 2016 em Curitiba.

${ }^{2}$ Graduada em Ciências Sociais pela Universidade Federal do Paraná. Especialista em Antropologia Social pela PUCPR. Endereço eletrônico: adrianeferrari2045@gmail.com
}

${ }^{3}$ Doutoranda em Sociologia do Programa de Pós-graduação da UFPR. Endereço eletrônico: anacvanali@ yahoo.com.br 
Cunha, Garcia Rodrigues Velho, o Capitão Manoel Ricam de Carvalho e o médico Paschoal Fernandes Leite, entre outros. Em 1837, a Capela de Nossa Senhora da Luz de Tindiqüera foi elevada a Capela Curada, um ano depois foram estabelecidas as primeiras divisas do bairro. Gradativamente, a população foi transferindo-se para as margens do Rio Iguaçu, e a sede do curato de Tindiquiera passa para o local em que estava a capela de "Nossa Senhora dos Remédios do Yguassú”. Através da Lei Provincial № 21, de 28 de fevereiro de 1858, foi criada a Freguezia de Nossa Senhora dos Remédios do Iguassú. Em 1868, a Freguezia do Iguassú foi desligada de Curitiba e anexada como distrito de São José dos Pinhais até 1888, quando volta a ser administrado por Curitiba. A criação do Município deve-se ao encaminhamento feito pelo Major Sezino Pereira de Souza (chefe político da região), redigido pelo médico Dr. Victor Ferreira do Amaral, de uma petição em forma de abaixo-assinado ao então Governador do Estado, o contra-almirante José Marques Guimarães, solicitando que a Freguezia do Iguassú fosse elevada a Vila e logo em seguida, fosse criado o Município. Assim, pelo Decreto Estadual $\mathrm{N}^{\circ}$ 40, de 11 de fevereiro de 1890, foi criado o Município de Araucária, que teve seu nome sugerido pelo Dr. Victor Ferreira do Amaral. A

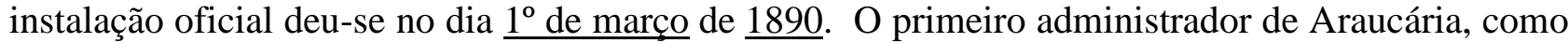
intendente, foi o Major Sezino Pereira de Souza. A primeira eleição municipal realizou-se no dia 22 de setembro de 1892, sendo o primeiro prefeito eleito de Araucária, Manoel Gonçalves Ferreira ${ }^{4}$ (Kersten, 1983).

\section{DECRETO No 40/1890}

O Contra Almirante José Marques Guimarães, Governador do Estado do Paraná, atendendo ao que lhe requerem os moradores da Freguezia do Iguassu e localidades vizinhas decreta:

Art. $1^{\circ}$. O povoado da Freguezia do Iguassú é elevado à categoria de vila, com a denominação de "Araucária".

Art. $2^{\circ}$. A Villa de Araucária será sede de um Município que terá por divisas: a leste, os rios das Antas, Maurício, Iguassu e Barigüy até a estrada da Villa do Rio Negro ao norte, em rumo do oeste, pelos limites da Colônia Thomáz Coelho até o Rio Verde a oeste por este Rio até o Iguassu, na foz do Ribeirão Izabel Alves até sua nascente d'ahi em procura das dos Rios Turvo que corta a estrada da Areia Branca até o Rio da Várzea ao sul por este Rio até a Foz das Antas.

Art. $3^{\circ}$. É nomeada uma Intendência Municipal para a Villa de Araucária, composta dos seguintes cidadãos: Presidente - Major Sezino Pereira de Souza Vice-Presidente - Capitão Veríssimo de Souza Marques Vogaes - Padre Francisco Soja, Major Joaquim Gonçalves Palhano, Antônio Arlindo Pereira, Francisco Ramiro Assis França e Valter Joslin.

Art. $4^{\circ}$. Ficam revogadas as disposições em contrário. 
Palácio do Governo do Estado do Paraná, em 11 de fevereiro de 1890. José Marques Guimarães ${ }^{5}$

No período de 1876, segundo a política imigratória de Lamenha Lins, que buscava fundar colônias de imigrantes nos arredores de Curitiba para abastecê-la de gêneros alimentícios, grupos de poloneses, alemães, italianos e ucranianos vem viver na região da Freguesia do Yguassú e fundam importantes colônias como a Thomaz Coelho (Wachowicz, 1975, 1977).

Com relação a atividade econômica do município, a exploração comercial da madeira iniciou-se na Freguesia do Iguassú a partir do século XIX, até a década de 1930, quando entra em crise pela devastação das reservas. Os moradores de Araucária ainda se dedicaram à exploração da erva-mate até a década de 1940, quando houve o declínio das exportações para a Argentina, que se tornou autossuficiente. O crescimento econômico da região proporcionou a abertura de mercado para outras atividades geradoras de emprego para a população como olarias, cerâmicas, moinhos, fábricas de palhões, de massa de tomate, de caixas de madeira, de linho, de fósforo, de balas, de bolachas e torrefação de café (Wachowicz, 1988).

A partir da década de 1970, ocorreu uma acentuada industrialização da cidade, totalizando o segundo maior parque fabril do estado, apenas atrás da capital. Em 1972, com a instalação da Refinaria Presidente Getúlio Vargas e em 1973 com a criação do CIAR (Centro Industrial de Araucária), ocorreu um crescimento bastante acentuado e uma inversão no quadro populacional, econômico e social do município, em que a população urbana passou a superar a rural com a vinda de um contingente populacional de vários pontos do país e a economia que se baseava na agricultura e pecuária passou a ser predominantemente industrial/urbana. Dentre as indústrias instaladas na cidade destacamos: FAFEN-PR, CSN Paraná, Siderúrgica Guaíra (Gerdau), Berneck, Cocelpa, Imcopa, Tri-Sure, Hübner Auto Linea, AAM do Brasil, Filtros Mil, Dyno do Brasil, Adesi, Gonvari do Brasil, Haus Technology, Trane e Novozymes (Oliveira, 2001).

O município atualmente tem uma economia bastante diversificada com um pólo industrial, produtos e serviços e ainda uma pequena porcentagem de produção agrícola. Segundo dados do IBGE (Instituto Brasileiro de Geografia e Estatística) a população estimada em 2015 era de 133.428 habitantes ${ }^{6}$. Dados do IPARDES (Instituto Paranaense de Desenvolvimento Econômico e Social)

\footnotetext{
${ }^{5}$ Disponível http://www.arquivopublico.pr.gov.br/. Acesso 29.fev.2016.

${ }^{6}$ Conforme http://cidades.ibge.gov.br/xtras/perfil.php?codmun=410180. Acesso em 29.fev.2016.
} 
indicam que até o período de 2014 existiam 96.418 eleitores ${ }^{7}$. O município de Araucária possui uma área territorial de 469,240 km e está distante 28 km do centro de Curitiba (Prefeitura, 2003).

\section{LOCALIZAÇÃO DE ARAUCÁRIA}

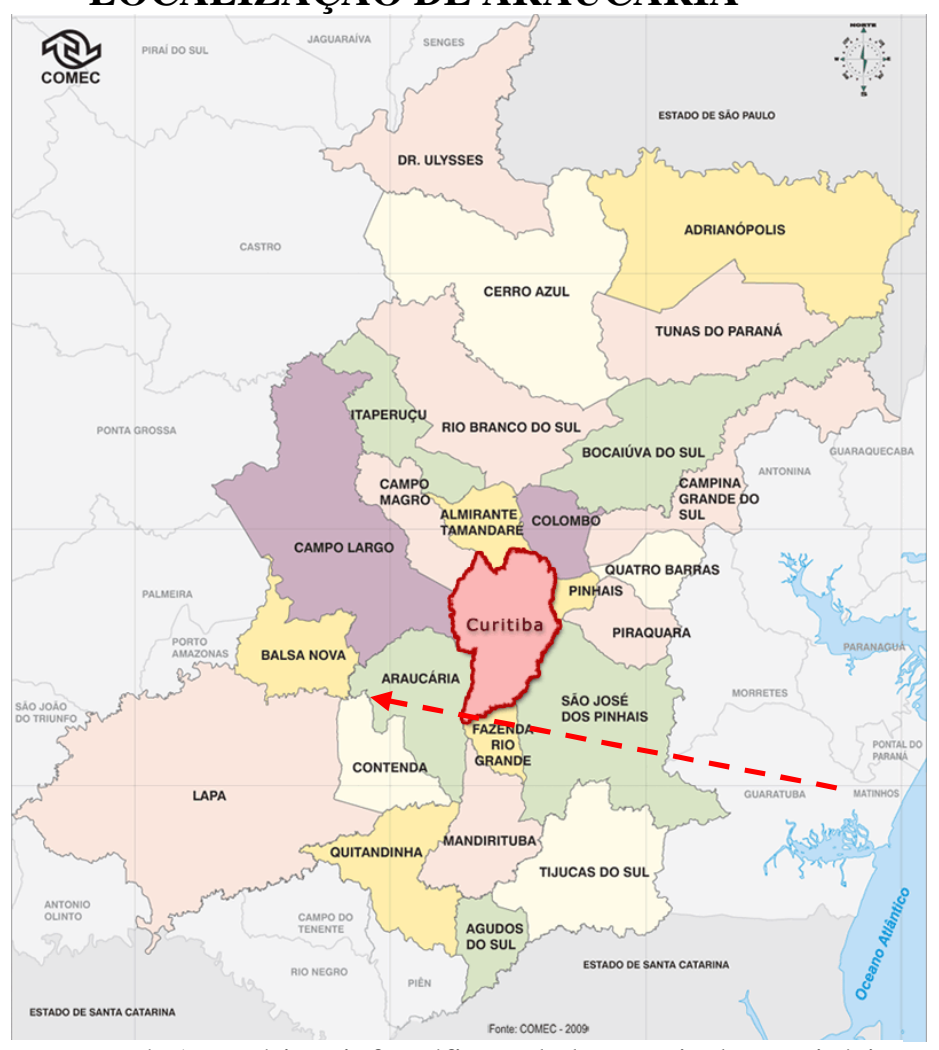

Fonte: Paraná. Araucária - infográficos: dados gerais do município.

Disponível em http://cod.ibge.gov.br/M47. Acesso 24.março.2016

${ }^{7}$ Disponível em http://www.ipardes.gov.br/. Acesso 13.abril.2016. 


\section{O PODER LEGISLATIVO EM ARAUCÁRIA}

Em 1890, quando da criação do município de Araucária, os primeiros representantes do Legislativo eram chamados "VOGAIS", e eram nomeados, conforme podemos ver no Decreto $\mathrm{N}^{\circ}$ 40 de criação do município.

PRIMEIRA REPÚBLICA: Governo Provisório

\begin{tabular}{|c|l|c|c|}
\hline \multicolumn{2}{|c|}{ Vogais de Araucária (1890-1892) } & Início Mandato & Fim Mandato \\
\hline 1 & Padre Francisco Soja & $11 / 02 / 1890$ & $14 / 06 / 1890$ \\
\hline 2 & Major Joaquim Gonçalves Palhano & $11 / 02 / 1890$ & $08 / 11 / 1890$ \\
\hline 3 & Antonio Arlindo Pereira & $11 / 02 / 1890$ & $01 / 05 / 1890$ \\
\hline 4 & Francisco Ramiro de Assis França & $11 / 02 / 1890$ & $08 / 11 / 1890$ \\
\hline 5 & Walter Joslin & $11 / 02 / 1890$ & $08 / 11 / 1890$ \\
\hline 6 & Pedro Hey & $01 / 05 / 1890$ & $07 / 04 / 1891$ \\
\hline 7 & Vicente Calderari & $18 / 06 / 1890$ & $07 / 04 / 1891$ \\
\hline 8 & Manoel Antonio da Rosa & $07 / 04 / 1890$ & $08 / 11 / 1891$ \\
\hline 9 & Manoel da Costa Guimarães & $07 / 04 / 1891$ & $08 / 11 / 1891$ \\
\hline 10 & Antonio Ferreira Mathozo Sobrinho & $25 / 04 / 1891$ & $08 / 11 / 1891$ \\
\hline 11 & Francelisio da Costa Pina & $08 / 11 / 1891$ & $25 / 09 / 1892$ \\
\hline 12 & Manoel Gonçalves Ferreira & $08 / 11 / 1891$ & $21 / 12 / 1891$ \\
\hline 13 & Vicente Calderari & $08 / 11 / 1891$ & $25 / 09 / 1892$ \\
\hline 14 & Francisco Ramiro de Assis França & $08 / 11 / 1891$ & $28 / 12 / 1891$ \\
\hline 15 & Antonio Ferreira Mathozo Sobrinho & $08 / 11 / 1891$ & $21 / 12 / 1891$ \\
\hline 16 & Pedro do Valle Ribeiro & $21 / 12 / 1891$ & $25 / 09 / 1892$ \\
\hline 17 & Joaquim de Oliveira Mello & $21 / 12 / 1891$ & $25 / 09 / 1892$ \\
\hline
\end{tabular}

FONTES: http://www.camaraaraucaria.pr.gov.br/ e http://politicaaraucaria. Acesso 29.fev.2016

\footnotetext{
8 Vogal é a pessoa que tem voto em assembleia, que é membro de junta, corporação, comissão, etc. Disponível
} Dicionário Priberam da Língua Portuguesa (2008-2013), http://www.priberam.pt/dlpo/. Acesso 29.fev.2016. 
O termo vogal foi utilizado durante o período do Governo Provisório, até 1892 quando foi substituído por camarista ${ }^{9}$, conforme a Constituição de 1891.

PRIMEIRA REPÚBLICA: após Constituição de 1891

\begin{tabular}{|c|l|c|c|}
\hline \multicolumn{2}{|c|}{ Camaristas de Araucária (1892-1930) } & Início Mandato & Fim Mandato \\
\hline 1 & Joaquim Ramos Ribeiro & $25 / 09 / 1892$ & $05 / 02 / 1894$ \\
\hline 2 & Vicente Calderari & $25 / 09 / 1892$ & $05 / 02 / 1894$ \\
\hline 3 & Francelísio da Costa Pina & $25 / 09 / 1892$ & $09 / 10 / 1893$ \\
\hline 4 & Fernando Suckow & $25 / 09 / 1892$ & $05 / 02 / 1894$ \\
\hline 5 & José Marzsolek & $25 / 09 / 1892$ & $05 / 02 / 1894$ \\
\hline 6 & Joaquim de Oliveira Mello & $25 / 09 / 1892$ & $29 / 04 / 1893$ \\
\hline 7 & Luiz Gomes de Amorim & $29 / 04 / 1893$ & $05 / 02 / 1894$ \\
\hline 8 & Antonio Agostinho de Miranda & $09 / 10 / 1893$ & $05 / 02 / 1894$ \\
\hline 9 & Francisco da Paula Câmara & $05 / 02 / 1894$ & $12 / 05 / 1894$ \\
\hline 10 & Francisco Ramiro de Assis França & $05 / 02 / 1894$ & $12 / 05 / 1894$ \\
\hline 11 & Bernardo Valentini & $05 / 02 / 1894$ & $12 / 05 / 1894$ \\
\hline 12 & Fernando Suckow & $05 / 02 / 1894$ & $12 / 05 / 1894$ \\
\hline 13 & Manoel da Costa Guimarães & $05 / 02 / 1894$ & $12 / 05 / 1894$ \\
\hline 14 & Rodolpho Hasselmann & $05 / 02 / 1894$ & $12 / 05 / 1894$ \\
\hline 15 & Joaquim Ramos Ribeiro & $12 / 05 / 1894$ & $22 / 07 / 1900$ \\
\hline 16 & Antonio Agostinho de Miranda & $12 / 05 / 1894$ & $22 / 07 / 1900$ \\
\hline 17 & Vicente Calderari & $12 / 05 / 1894$ & $22 / 09 / 1904$ \\
\hline 18 & Lourenço Grabowski & $12 / 05 / 1894$ & $22 / 09 / 1904$ \\
\hline 19 & Luiz Gomes de Amorim & $12 / 05 / 1894$ & $22 / 07 / 1900$ \\
\hline 20 & Inácio de Paula Lopes & $12 / 05 / 1894$ & $22 / 07 / 1900$ \\
\hline 21 & Eugenio dos Santos Justen & $22 / 07 / 1900$ & $22 / 09 / 1904$ \\
\hline 22 & João Leite Furtado & $22 / 07 / 1900$ & $22 / 09 / 1904$ \\
\hline 23 & Theolindo Gonçalves Ferreira & $22 / 09 / 1904$ & $29 / 03 / 1905$ \\
\hline 24 & Joaquim de Oliveira Melo & $22 / 09 / 1904$ & $21 / 07 / 1908$ \\
\hline 25 & Barnabé José da Costa & $22 / 09 / 1904$ & $29 / 03 / 1905$ \\
\hline 26 & Marciano de Souza Carneiro & $22 / 09 / 1904$ & $21 / 07 / 1908$ \\
\hline 27 & Lindolpho Ferreira Mathozo & $22 / 09 / 1904$ & $21 / 07 / 1908$ \\
\hline 28 & João Ferreira da Motta & $22 / 09 / 1904$ & $21 / 07 / 1908$ \\
\hline 29 & Camilo de Andrade & $01 / 07 / 1905$ & $21 / 07 / 1908$ \\
\hline 30 & Lucindo de Andrade & $01 / 07 / 1905$ & $21 / 07 / 1908$ \\
\hline 31 & Francisco Marzsolek & $21 / 07 / 1908$ & $20 / 06 / 1912$ \\
\hline 32 & João Izidoro da Silva & $21 / 07 / 1908$ & $20 / 06 / 1912$ \\
\hline 33 & Ernesto Alfredo Buschman & $21 / 07 / 1908$ & $20 / 06 / 1912$ \\
\hline 34 & José Tyrka & $21 / 07 / 1908$ & $20 / 06 / 1912$ \\
\hline 35 & Antonio Alves Pinto & $21 / 07 / 1908$ & $20 / 06 / 1912$ \\
\hline 36 & Jorge Miguel & $21 / 07 / 1908$ & $20 / 06 / 1912$ \\
\hline 37 & Arthur Santos & $20 / 06 / 1912$ & $30 / 11 / 1918$ \\
\hline 38 & Pedro Nolasco Pizzato & $20 / 06 / 1912$ & $20 / 09 / 1920$ \\
\hline
\end{tabular}

${ }^{9}$ Camarista é o vereador, membro da Câmara Municipal. Disponível Dicionário Priberam da Língua Portuguesa (20082013), http://www.priberam.pt/dlpo/. Acesso 29.fev.2016. 


\begin{tabular}{|l|l|l|l|}
\hline 39 & Evaristo Pedroso & $20 / 06 / 1912$ & $20 / 09 / 1920$ \\
\hline 40 & Pedro Schilnas & $20 / 06 / 1912$ & $21 / 09 / 1916$ \\
\hline 41 & Paulo Rychova & $20 / 06 / 1912$ & $21 / 09 / 1916$ \\
\hline 42 & Polycarpo Gonçalves Ferreira & $21 / 09 / 1916$ & $20 / 09 / 1920$ \\
\hline 43 & Julio Szymanski & $21 / 09 / 1916$ & $20 / 09 / 1920$ \\
\hline 44 & Miguel Bertolino Pizzato & $20 / 09 / 1920$ & $21 / 09 / 1924$ \\
\hline 45 & Pedro Schilnas & $20 / 09 / 1920$ & $21 / 09 / 1924$ \\
\hline 46 & Heitor Alves Guimarães & $21 / 09 / 1920$ & $21 / 09 / 1924$ \\
\hline 47 & Bento Luiz de França & $20 / 09 / 1920$ & $21 / 09 / 1924$ \\
\hline 48 & Máximo Cantador & $20 / 09 / 1920$ & $21 / 09 / 1924$ \\
\hline 49 & João Izidoro da Silva & $20 / 09 / 1920$ & $21 / 09 / 1924$ \\
\hline 50 & Bernardo Valentini & $20 / 09 / 1920$ & $21 / 09 / 1924$ \\
\hline 51 & João Chichon & $20 / 09 / 1920$ & $21 / 09 / 1924$ \\
\hline 52 & Joaquim Ramos Ribeiro & $21 / 09 / 1924$ & $21 / 09 / 1928$ \\
\hline 53 & Gustavo Suckow & $21 / 09 / 1924$ & $21 / 09 / 1928$ \\
\hline 54 & Miguel Grabowski & $21 / 09 / 1924$ & $09 / 10 / 1930$ \\
\hline 55 & Victor Gomes da Costa & $21 / 09 / 1924$ & $09 / 10 / 1930$ \\
\hline 56 & Romão Grabarski & $21 / 09 / 1924$ & $21 / 09 / 1928$ \\
\hline 57 & Estanislau Trauczynski Sobrinho & $21 / 09 / 1928$ & $09 / 10 / 1930$ \\
\hline 58 & Pedro Sferelli & $21 / 09 / 1928$ & $09 / 10 / 1930$ \\
\hline 59 & Pedro Orlikoski & $21 / 09 / 1928$ & $09 / 10 / 1930$ \\
\hline 60 & José Druszcz & $21 / 09 / 1928$ & $01 / 07 / 1930$ \\
\hline 61 & Luiz Karas & $03 / 07 / 1930$ & $09 / 10 / 1930$ \\
\hline
\end{tabular}

FONTES: http://www.camaraaraucaria.pr.gov.br/ e http://politicaaraucaria. Acesso 29.fev.2016

A Constituição de 1934 adota o termo vereador para os legisladores municipais. Somente após a Constituição de 1946 as legislaturas passam a ser contadas. Atualmente o município de Araucária está em sua $16^{\mathrm{a}}$ legislatura, preparando as eleições para a $17^{\mathrm{a}}$ (2017-2020). O quadro legislativo municipal atualmente é composto de 11 vereadores. O número de vereadores é proporcional à população do município, conforme artigo 29 , IV da Constituição de $1988^{10}$. Segue relação com os nomes dos representantes do Poder Legislativo de Araucária a partir da $1^{\text {a }}$ Legislatura:

\footnotetext{
${ }^{10}$ Disponível em http://www.planalto.gov.br/ccivil 03/constituicao. Acesso 29.fev.2016.
} 
ERA VARGAS: após Constituição de 1934

\begin{tabular}{|c|l|c|c|}
\hline \multicolumn{3}{|c|}{ Legislatura 1936-1941 } \\
\hline & Vereadores & Início Mandato & Fim Mandato \\
\hline 1 & Estanislau Trauczynski Sobrinho & $14 / 02 / 1936$ & $06 / 02 / 1941$ \\
\hline 2 & Guilherme Falat & $14 / 02 / 1936$ & $24 / 09 / 1937$ \\
\hline 3 & Carlos Augusto Rodolpho Damm & $14 / 02 / 1936$ & $13 / 07 / 1936$ \\
\hline 4 & Ernesto Bucholtz & $14 / 02 / 1936$ & $06 / 02 / 1941$ \\
\hline 5 & Francisco Carrano Júnior & $14 / 02 / 1936$ & $06 / 02 / 1941$ \\
\hline 6 & Neves Joslin & $14 / 02 / 1936$ & $18 / 09 / 1936$ \\
\hline 7 & André Skraba & $25 / 09 / 1936$ & $06 / 02 / 1941$ \\
\hline 8 & Miguel Lesniowski & $24 / 09 / 1936$ & $06 / 02 / 1941$ \\
\hline
\end{tabular}

FONTES: http://www.camaraaraucaria.pr.gov.br/ e http://politicaaraucaria. Acesso 29.fev.2016

\section{APÓS ESTADO NOVO}

\begin{tabular}{|l|l|}
\hline \multicolumn{2}{|c|}{$1^{\text {a }}$ Legislatura (07/12/1947 a 07/12/1951) } \\
\hline 1 & Álvaro Cantador \\
\hline 2 & Archelau de Almeida Torres \\
\hline 3 & Boleslau Wzorek \\
\hline 4 & Estanislau Lesniowski \\
\hline 5 & Francisco Ribeiro Cardoso \\
\hline 6 & Francisco Skraba \\
\hline 7 & José Haiduk \\
\hline 8 & Mieceslau Jasiocha \\
\hline 9 & Romualdo Sobocinski \\
\hline & Daniel Incot (suplente que assumiu) \\
\hline & João Brunato (suplente que assumiu) \\
\hline
\end{tabular}

FONTES: http://www.camaraaraucaria.pr.gov.br/ e http://politicaaraucaria. Acesso 29.fev.2016

\begin{tabular}{|l|l|}
\hline \multicolumn{2}{|c|}{$\mathbf{2}^{\mathbf{a}}$ Legislatura (08/12/1951 a 07/12/1955) } \\
\hline 1 & Alderico Zanardine Ozório \\
\hline 2 & Ambrósio Campanholo \\
\hline 3 & Francisco Ribeiro Cardoso \\
\hline 4 & João José Valentini \\
\hline 5 & Mieceslau Jasiocha \\
\hline 6 & Odilon Carrano \\
\hline 7 & Pedro Glir \\
\hline 8 & Vergílio Alves Pinto \\
\hline & Alberto Pansolin (suplente que assumiu) \\
\hline & Francisco Gondek (suplente que assumiu) \\
\hline & Reynaldo Rigon (suplente que assumiu) \\
\hline
\end{tabular}

FONTES: http://www.camaraaraucaria.pr.gov.br/ e http://politicaaraucaria. Acesso 29.fev.2016 


\begin{tabular}{|l|l|}
\hline \multicolumn{2}{|c|}{$\mathbf{3}^{\mathbf{a}}$ Legislatura $(\mathbf{0 8 / 1 2 / 1 9 5 5}$ a 08/12/1959) } \\
\hline 1 & Francisco Ribeiro Cardoso \\
\hline 2 & José Furman \\
\hline 3 & Miguel Burda \\
\hline 4 & Odilon Carrano \\
\hline 5 & Reynaldo Alves Pinto \\
\hline 6 & Romualdo Sobocinski \\
\hline 7 & Walentin Wolski \\
\hline 8 & Wenceslau Jasiocha \\
\hline
\end{tabular}

FONTES: http://www.camaraaraucaria.pr.gov.br/ e http://politicaaraucaria. Acesso 29.fev.2016

\begin{tabular}{|l|l|}
\hline \multicolumn{2}{|c|}{$\mathbf{4}^{\text {a }}$ Legislatura $(\mathbf{0 9 / 1 2 / 1 9 5 9}$ a 08/12/1963) } \\
\hline 1 & Álvaro Cantador \\
\hline 2 & Benedito B. Fontoura \\
\hline 3 & Celso Traczynski \\
\hline 4 & Estanislau Novinski \\
\hline 5 & Francisco Ribeiro Cardoso \\
\hline 6 & José Muchau \\
\hline 7 & Odilon Carrano \\
\hline 8 & Reynaldo Alves Pinto \\
\hline & Arthur Kicot (suplente que assumiu) \\
\hline & Boleslau Rossot (suplente que assumiu) \\
\hline & João Doering Gorski (suplente que assumiu) \\
\hline & Jorge Abud (suplente que assumiu) \\
\hline & Luiz Felício Anad (suplente que assumiu) \\
\hline
\end{tabular}

FONTES: http://www.camaraaraucaria.pr.gov.br/ e http://politicaaraucaria. Acesso 29.fev.2016

\begin{tabular}{|l|l|}
\hline \multicolumn{2}{|c|}{$\mathbf{5}^{\text {a }}$ Legislatura (09/12/1963 a 31/01/1969) } \\
\hline 1 & Antonio João Franceschi \\
\hline 2 & Antonio Pinto Neto \\
\hline 3 & Eduardo José Wolski \\
\hline 4 & Francisco Ribeiro Cardoso \\
\hline 5 & Jerônimo de A. Maranhão \\
\hline 6 & Jorge Abud \\
\hline 7 & José Knopik \\
\hline 8 & Reynaldo Alves Pinto \\
\hline & Anselmo Antonio Negrelle (suplente que assumiu) \\
\hline & Attilio Pereira de Lima (suplente que assumiu) \\
\hline & Bernardo Valentini Neto (suplente que assumiu) \\
\hline & João Tulio do Valle (suplente que assumiu) \\
\hline & Miguel Burda (suplente que assumiu) \\
\hline
\end{tabular}

FONTES: http://www.camaraaraucaria.pr.gov.br/ e http://politicaaraucaria. Acesso 29.fev.2016 


\begin{tabular}{|l|l|}
\hline \multicolumn{2}{|c|}{$\mathbf{6}^{\text {a }}$ Legislatura (01/01/1970 a 31/01/1973) } \\
\hline 1 & Emílio Ferreira da Silva \\
\hline 2 & Francisco Ribeiro Cardoso \\
\hline 3 & João Doering Gorski \\
\hline 4 & Jorge Abud \\
\hline 5 & Meftódio Ohppis \\
\hline 6 & Pedro Sfendrych \\
\hline 7 & Reynaldo Rigon \\
\hline 8 & Teófilo Knopik \\
\hline & Albanor Costenaro (suplente que assumiu) \\
\hline & Antonio Gunha (suplente que assumiu) \\
\hline & Carlos Massaro Kaimoto (suplente que assumiu) \\
\hline
\end{tabular}

FONTES: http://www.camaraaraucaria.pr.gov.br/ e http://politicaaraucaria. Acesso 29.fev.2016

\begin{tabular}{|l|l|}
\hline \multicolumn{2}{|c|}{$\mathbf{7}^{\mathbf{a}}$ Legislatura (01/02/1973 a 01/02/1977) } \\
\hline 1 & Acyr de Almeida Torres \\
\hline 2 & Aleixo Skraba \\
\hline 3 & Attilio Pereira de Lima \\
\hline 4 & Edvino Wzorek \\
\hline 5 & Emilio Ferreira da Silva \\
\hline 6 & Emilio Cunha \\
\hline 7 & Francisco Mario Franceschi \\
\hline 8 & Jorge Abud \\
\hline 9 & Odemar de Oliveira \\
\hline & Daniel Muchau (suplente que assumiu) \\
\hline
\end{tabular}

FONTES: http://www.camaraaraucaria.pr.gov.br/ e http://politicaaraucaria. Acesso 29.fev.2016

\begin{tabular}{|c|l|}
\hline \multicolumn{2}{|c|}{$\mathbf{8}^{\text {a }}$ Legislatura $(\mathbf{0 2 / 0 2 / 1 9 7 7 ~ a ~ 3 1 / 0 1 / 1 9 8 3 )}$} \\
\hline 1 & Acyr de Almeida Torres \\
\hline 2 & Alcir Nogueira \\
\hline 3 & Aldair Miguel Biar \\
\hline 4 & Edvino Wzorek \\
\hline 5 & Emilio Ferreira da Silva \\
\hline 6 & Gustavo de Oliveira Padilha \\
\hline 7 & Jorge Abud \\
\hline 8 & Leopoldo Luiz Tuleski \\
\hline 9 & Ludovico Gondek \\
\hline
\end{tabular}

FONTES: http://www.camaraaraucaria.pr.gov.br/ e http://politicaaraucaria. Acesso 29.fev.2016 


\begin{tabular}{|l|l|}
\hline \multicolumn{2}{|c|}{$9^{\text {a }}$ Legislatura $(\mathbf{0 1 / 0 2 / 1 9 8 3 ~ a ~ 3 1 / 1 2 / 1 9 8 8 )}$} \\
\hline 1 & Acyr de Almeida Torres \\
\hline 2 & Alcir Nogueira \\
\hline 3 & Aldair Miguel Biar \\
\hline 4 & Algacir Ohpis \\
\hline 5 & João Alceu Souza Rodrigues \\
\hline 6 & Josué de Oliveira Kersten \\
\hline 7 & Pedro Furman \\
\hline 8 & Pedro Paulo Kalva Filho \\
\hline 9 & Pedro Sebastião do Valle Lemos \\
\hline & Antonio Aleixo Wagner (suplente que assumiu) \\
\hline
\end{tabular}

FONTES: http://www.camaraaraucaria.pr.gov.br/ e http://politicaaraucaria. Acesso 29.fev.2016

\begin{tabular}{|l|l|}
\hline \multicolumn{1}{|c|}{$\mathbf{1 0}^{\mathbf{a}}$ Legislatura (01/01/1989 a 31/12/1992) } \\
\hline $\mathbf{1}^{\mathbf{0}}$ BIÊNIO \\
Presidente: Olizandro José Ferreira \\
$\begin{array}{l}\mathbf{2}^{\mathbf{o}} \text { BIÊNIO } \\
\text { Presidente: Ademir Paiola }\end{array}$ \\
\hline 1 & Ademir Paiola \\
\hline 2 & Alcir Nogueira \\
\hline 3 & Aldair Miguel Buiar \\
\hline 4 & Irineu Cantador \\
\hline 5 & João Renato Cantelle \\
\hline 6 & Josué de Oliveira Kersten \\
\hline 7 & Mauro Luiz Biscaia \\
\hline 8 & Olizandro José Ferreira \\
\hline 9 & Pedro Furman \\
\hline
\end{tabular}

FONTES: http://www.camaraaraucaria.pr.gov.br/ e http://politicaaraucaria. Acesso 29.fev.2016 


\begin{tabular}{|c|c|}
\hline & $11^{\mathrm{a}}$ Legislatura (01/01/1993 a 31/12/1996) \\
\hline $\begin{array}{l}1^{\circ} \mathrm{F} \\
\text { Pre } \\
2^{\circ} \mathrm{F} \\
\text { Pre }\end{array}$ & $\begin{array}{l}\text { IÊNIO } \\
\text { idente: Olizandro José Ferreira } \\
\text { IÊNIO } \\
\text { idente: Irineu Cantador }\end{array}$ \\
\hline 1 & Alcir Nogueira \\
\hline 2 & Aldair Miguel Buiar \\
\hline 3 & Irineu Cantador \\
\hline 4 & João Renato Cantelle \\
\hline 5 & José Juval Bezerra \\
\hline 6 & Josué de Oliveira Kersten \\
\hline 7 & Luiz Soczek \\
\hline 8 & Mauro Luiz Biscaia \\
\hline 9 & Olizando José Ferreira \\
\hline 10 & Ozório Pereira \\
\hline 11 & Paulo Sabag \\
\hline 12 & Sebastião Cordeiro Calado \\
\hline 13 & Wilson David Mota \\
\hline
\end{tabular}

FONTES: http://www.camaraaraucaria.pr.gov.br/ e http://politicaaraucaria. Acesso 29.fev.2016

\section{$12^{\mathrm{a}}$ Legislatura $(01 / 01 / 1997$ a 31/12/2000)}

\section{$1^{\circ}$ BIÊNIO}

Presidente: João Renato Cantelle

\section{$2^{\circ}$ BIÊNIO}

Presidente: Olizandro José Ferreira

\begin{tabular}{|c|l|}
\hline 1 & Alceu Valério da Silva \\
\hline 2 & Alcir Nogueira \\
\hline 3 & Algacir Ohpis \\
\hline 4 & Clodoaldo Nepomuceno Pinto Junior \\
\hline 5 & Francisco Carlos Cabrini \\
\hline 6 & Inácio Mikosz \\
\hline 7 & João Renato Cantelle \\
\hline 8 & José Juval Bezerra \\
\hline 9 & Luiz Soczek \\
\hline 10 & Olizandro José Ferreira \\
\hline 11 & Ozório Pereira \\
\hline 12 & Paulo Sabbag \\
\hline 13 & Pedro Furman \\
\hline 14 & Sebastião Cordeiro Calado \\
\hline 15 & Wilson Roberto David Mota \\
\hline
\end{tabular}

FONTES: http://www.camaraaraucaria.pr.gov.br/ e http://politicaaraucaria. Acesso 29.fev.2016 


\section{$13^{\mathrm{a}}$ Legislatura $(01 / 01 / 2001$ a 31/12/2004)}

\section{$1^{\circ}$ BIÊNIO}

Presidente: Wilson Roberto David Motta

\section{$2^{\circ}$ BIÊNIO}

Presidente: Irineu Cantador

\begin{tabular}{|c|c|c|c|c|c|c|c|}
\hline \multicolumn{2}{|r|}{ Vereadores } & \multirow{2}{*}{$\begin{array}{c}\begin{array}{c}\text { Filiação } \\
\text { Partidária }\end{array} \\
\text { PRN } \\
\end{array}$} & \multirow{2}{*}{$\begin{array}{c}\begin{array}{c}\text { Qtde } \\
\text { votos }\end{array} \\
773 \\
\end{array}$} & \multirow{2}{*}{$\begin{array}{c}\text { Data } \\
\text { Nascimento } \\
06 / 08 / 1952 \\
\end{array}$} & \multirow{2}{*}{$\begin{array}{c}\text { Est. Civil } \\
\text { casado }\end{array}$} & \multirow{2}{*}{$\begin{array}{c}\text { Escolaridade } \\
\text { Fundamental incompleto } \\
\end{array}$} & \multirow{2}{*}{$\begin{array}{c}\text { Profissão } \\
\text { administrador } \\
\end{array}$} \\
\hline 1 & Amir Júlio Russi & & & & & & \\
\hline 2 & $\begin{array}{l}\text { Clodoaldo Nepomuceno } \\
\text { Pinto Júnior }\end{array}$ & PDT & 1648 & $29 / 07 / 1955$ & casado & Superior completo & engenheiro \\
\hline 3 & Francisco Carlos Cabrini & $\mathrm{PP}$ & 1087 & $09 / 10 / 1970$ & casado & Médio completo & comerciante \\
\hline 4 & Inácio Mikosz & PFL & 627 & $21 / 04 / 1948$ & casado & Superior completo & economista \\
\hline 5 & Irineu Cantador & PPS & 1212 & $16 / 01 / 1958$ & casado & Superior completo & despachante \\
\hline 6 & João Renato Cantelle & PTB & 1124 & $09 / 11 / 1951$ & solteiro & Médio incompleto & \\
\hline 7 & $\begin{array}{l}\text { Jorge Fernando } \\
\text { Zimmermann }\end{array}$ & PSDB & 671 & $17 / 01 / 1953$ & casado & Médio completo & publicitário \\
\hline 8 & José Juval Bezerra & PSDB & 619 & $27 / 12 / 1937$ & casado & Fundamental completo & \\
\hline 9 & Josué de Oliveira Kersten & PDT & 985 & $20 / 08 / 1949$ & casado & Superior completo & médico \\
\hline 10 & Marilda Gilinski & PTB & 515 & $20 / 04 / 1958$ & viúva & Fundamental incompleto & comerciante \\
\hline 11 & Oilson Muller & PRN & 858 & $12 / 11 / 1960$ & casado & Médio completo & comerciante \\
\hline 12 & Ozório Pereira & PSL & 891 & $07 / 07 / 1942$ & casado & Fundamental incompleto & $\begin{array}{l}\text { servidor público } \\
\text { municipal }\end{array}$ \\
\hline 13 & Robison Ricardo Furman & PFL & 750 & $29 / 07 / 1976$ & casado & Superior incompleto & empresário \\
\hline 14 & Ronaldo de Assis Martins & PPS & 924 & $28 / 04 / 1962$ & casado & Médio completo & comerciante \\
\hline 15 & Sebastião Cordeiro Calado & PFL & 602 & $29 / 05 / 1951$ & casado & Médio incompleto & radialista/locutor \\
\hline 16 & $\begin{array}{l}\text { Wilson Roberto David } \\
\text { Mota }\end{array}$ & PSDB & 1176 & $07 / 09 / 1962$ & casado & Superior completo & agrônomo/advogado \\
\hline & $\begin{array}{l}\text { Pedro Ferreira de Lima } \\
\text { (suplente que assumiu) }\end{array}$ & PDT & 517 & $10 / 08 / 1967$ & casado & Fundamental completo & comerciante \\
\hline & $\begin{array}{l}\text { Rosicler Regina Almeida de } \\
\text { Souza }^{11} \text { (suplente que } \\
\text { assumiu) }\end{array}$ & PDT & 1236 & $14 / 031964$ & divorciada & Superior completo & professora \\
\hline & $\begin{array}{l}\text { José Carlos dos Santos } \\
\text { (suplente que assumiu) }\end{array}$ & PSL & 159 & $23 / 01 / 1954$ & casado & Médio completo & pastor \\
\hline
\end{tabular}

FONTES: http://www.camaraaraucaria.pr.gov.br/, http://politicaaraucaria e https://apps.tre-pr.jus.br,

http://www.tse.jus.br/eleicoes/eleicoes-anteriores/eleicoes-2000/resultado-da-eleicao-2000. Acesso 29.fev.2016

${ }^{11}$ Substituiu Clodoaldo Nepomuceno que assumiu a Secretaria Municipal de Obras Públicas em 04.01.2001. 


\section{$14^{\mathrm{a}}$ Legislatura $(01 / 01 / 2005$ a $31 / 12 / 2008)$}

\section{$1^{\circ}$ BIÊNIO}

Presidente: Francisco Carlos Cabrini

\section{$2^{\circ}$ BIÊNIO}

Presidente: Esmael Antonio Ferreira Padilha

\begin{tabular}{|c|c|c|c|c|c|c|c|}
\hline \multicolumn{2}{|r|}{ Vereadores } & \multirow{2}{*}{$\begin{array}{c}\begin{array}{c}\text { Filiação } \\
\text { Partidária }\end{array} \\
\text { PP } \\
\end{array}$} & \multirow{2}{*}{$\begin{array}{l}\text { Qtde } \\
\text { votos } \\
2466 \\
\end{array}$} & \multirow{2}{*}{$\begin{array}{c}\begin{array}{c}\text { Data } \\
\text { Nascimento }\end{array} \\
09 / 10 / 1970 \\
\end{array}$} & \multirow{2}{*}{$\begin{array}{c}\text { Est. Civil } \\
\text { casado } \\
\end{array}$} & \multirow{2}{*}{$\begin{array}{l}\text { Escolaridade } \\
\text { Médio completo } \\
\end{array}$} & \multirow{2}{*}{$\begin{array}{c}\text { Profissão } \\
\text { comerciante } \\
\end{array}$} \\
\hline 1 & Francisco Carlos Cabrini & & & & & & \\
\hline 2 & Irineu Cantador & PL & 3919 & $16 / 01 / 1958$ & casado & Superior completo & despachante \\
\hline 3 & João Renato Cantelle & PTB & 2458 & $09 / 11 / 1951$ & solteiro & Médio incompleto & \\
\hline 4 & Josué de Oliveira Kersten & PTN & 3478 & $20 / 08 / 1949$ & casado & Superior completo & médico \\
\hline 5 & Lucínio Leônidas Grebos & $\mathrm{PL}$ & 2485 & $21 / 12 / 1955$ & casado & Superior completo & cargo em comissão \\
\hline 6 & $\begin{array}{l}\text { Luis Fernando Emílio } \\
\text { Coimbra }\end{array}$ & PFL & 2084 & 27/08/1969 & casado & Médio completo & comerciante \\
\hline 7 & $\begin{array}{l}\text { Luiz Henrique Ozório } \\
\text { Vicente }\end{array}$ & PSDB & 2412 & 01/05/1961 & casado & Médio incompleto & comerciante \\
\hline 8 & Pedro Ferreira de Lima & PDT & 3230 & 10/08/1967 & casado & Fundamental completo & comerciante \\
\hline 9 & Renaldo Rodrigues & PDT & 2276 & $01 / 06 / 1966$ & casado & Médio completo & comerciante \\
\hline 10 & Wilson Roberto David Mota & PSDB & 3489 & $07 / 09 / 1962$ & casado & Superior completo & agrônomo/advogado \\
\hline & $\begin{array}{l}\text { Amir Julio Russi (suplente } \\
\text { que assumiu) }\end{array}$ & PMDB & 1247 & 06/08/1952 & casado & Fundamental completo & agricultor \\
\hline & $\begin{array}{l}\text { Rui Sérgio Alves de Souza } \\
\text { (suplente que assumiu) }\end{array}$ & PTN & 1305 & $13 / 11 / 1963$ & casado & Superior completo & professor \\
\hline
\end{tabular}

FONTES: http://www.camaraaraucaria.pr.gov.br/, http://politicaaraucaria e https://apps.tre-pr.jus.br,

http://www.tse.jus.br/eleicoes/eleicoes-anteriores/eleicoes-2004/resultado-da-eleicao-2004. Acesso 29.fev.2016 


\section{$1^{\circ}$ BIÊNIO}

Presidente: Rui Sergio Alves de Souza

$\mathbf{1}^{\mathbf{o}}$ Vice-Presidente: Alan Henning

$2^{\mathbf{o}}$ Vice-Presidente: Pedro Gilmar Nogueira

$1^{\circ}$ Secretário: Clodoaldo Nepomuceno Pinto Junior

$2^{\text {a }}$ Secretária: Adriana Cocci de Moraes Castro

\section{$2^{\circ}$ BIÊNIO}

Presidente: Pedro Ferreira de Lima

$1^{\circ}$ Vice-Presidente: Clodoaldo Nepomuceno Pinto Junior

$2^{\circ}$ Vice-Presidente: Esmael Antonio Ferreira Padilha

$1^{\circ}$ Secretário: Rui Sérgio Alves de Souza

$2^{\mathbf{o}}$ Secretário: Alan Henning

\begin{tabular}{|c|l|c|c|c|c|c|c|}
\hline \multicolumn{2}{|c|}{ Vereadores } & $\begin{array}{c}\text { Filiação } \\
\text { Partidária }\end{array}$ & $\begin{array}{c}\text { Qtde } \\
\text { votos }\end{array}$ & $\begin{array}{c}\text { Data } \\
\text { Nascimento }\end{array}$ & Est. Civil & Escolaridade \\
\hline 1 & $\begin{array}{l}\text { Adriana Cocci de Moraes } \\
\text { Castro }\end{array}$ & PTN & 2409 & $30 / 04 / 1972$ & casada & Superior completo \\
\hline 2 & Alex Luiz Nogueira & PSDB & 1861 & $06 / 10 / 1977$ & solteiro & Médio completo & comerciante \\
\hline 3 & Alan Henning & PMDB & 3016 & $15 / 09 / 1974$ & casado & Médio completo & comerciante \\
\hline 4 & $\begin{array}{l}\text { Clodoaldo Nepomuceno } \\
\text { Pinto Junior }\end{array}$ & PDT & 1518 & $29 / 07 / 1955$ & casado & Superior completo \\
\hline 4 & $\begin{array}{l}\text { Esmael Antonio Ferreira } \\
\text { Padilha }\end{array}$ & PSL & 2292 & $30 / 06 / 1965$ & casado & Médio completo & cargo em comissão \\
\hline 6 & Francisco Carlos Cabrini & PP & 2377 & $09 / 10 / 1970$ & casado & Médio completo & comerciante \\
\hline 7 & Ismael Cantador & PTB & 1996 & $08 / 07 / 1956$ & casado & Superior completo & economista \\
\hline 8 & Pedro Ferreira de Lima & PMDB & 2782 & $11 / 02 / 1960$ & casado & Fundamental completo & motorista particular \\
\hline 9 & Pedro Gilmar Nogueira & PTN & 1777 & $10 / 08 / 1967$ & casado & Médio completo & comerciante \\
\hline 10 & $\begin{array}{l}\text { Rui Sérgio Alves de } \\
\text { Souza }\end{array}$ & PT & 2027 & $13 / 11 / 1963$ & casado & Superior completo & professor \\
\hline 11 & $\begin{array}{l}\text { Wilson Roberto David } \\
\text { Mota }\end{array}$ & PSD & 1798 & $07 / 09 / 1962$ & casado & Superior completo & agrônomo/advogado \\
\hline
\end{tabular}

FONTES: http://www.camaraaraucaria.pr.gov.br/, http://politicaaraucaria e https://apps.tre-pr.jus.br,

http://www.tse.jus.br/eleicoes/eleicoes-anteriores/eleicoes-2008/resultado-da-eleicao-2008. Acesso 29.fev.2016 


\section{$16^{a}$ Legislatura $(01 / 01 / 2013$ a 31/12/2016)}

\section{$1^{\circ}$ BIÊNIO}

Presidente: Pedro Gilmar Nogueira

$\mathbf{1}^{\mathbf{6}}$ Vice-Presidente: Vanderlei Francisco de Oliveira

$2^{\circ}$ Vice-Presidente: Paulo Henrique Areias Horácio

$1^{\circ}$ Secretário: Alex Luiz Nogueira

$2^{\mathbf{o}}$ Secretário: Wilson Roberto David Mota

\section{$2^{\circ}$ BIÊNIO}

Presidente: Wilson Roberto David Mota

$1^{\circ}$ Vice-Presidente: Alex Luiz Nogueira

$2^{\mathbf{o}}$ Vice-Presidente: Pedro Gilmar Nogueira

$1^{a}$ Secretária: Adriana Cocci de Moraes Castro

$2^{\mathbf{o}}$ Secretário: Vanderlei Francisco de Oliveira

\begin{tabular}{|c|c|c|c|c|c|c|c|}
\hline \multicolumn{2}{|r|}{ Vereadores } & \multirow{2}{*}{$\begin{array}{c}\begin{array}{c}\text { Filiação } \\
\text { Partidária }\end{array} \\
\text { PTN }\end{array}$} & \multirow{2}{*}{$\begin{array}{l}\text { Qtde } \\
\text { votos } \\
2196\end{array}$} & \multirow{2}{*}{$\begin{array}{c}\begin{array}{c}\text { Data } \\
\text { Nascimento }\end{array} \\
30 / 04 / 1972\end{array}$} & \multirow{2}{*}{$\begin{array}{c}\text { Est. Civil } \\
\text { casada }\end{array}$} & \multirow{2}{*}{$\begin{array}{c}\text { Escolaridade } \\
\text { Superior completo }\end{array}$} & \multirow{2}{*}{$\begin{array}{c}\text { Profissão } \\
\text { comerciante }\end{array}$} \\
\hline 1 & $\begin{array}{l}\text { Adriana Cocci de Moraes } \\
\text { Castro }\end{array}$ & & & & & & \\
\hline 2 & Alex Luiz Nogueira & PSDB & 3325 & $06 / 10 / 1977$ & solteiro & Médio completo & comerciante \\
\hline 3 & $\begin{array}{l}\text { Clodoaldo Nepomuceno } \\
\text { Pinto Junior }\end{array}$ & PT & 2016 & $29 / 07 / 1955$ & casado & Superior completo & engenheiro \\
\hline 4 & $\begin{array}{l}\text { Esmael Antonio Ferreira } \\
\text { Padilha }\end{array}$ & PSL & 2393 & $30 / 06 / 1965$ & casado & Médio completo & cargo em comissão \\
\hline 4 & Francisco Carlos Cabrini & $\mathrm{PP}$ & 2365 & $09 / 10 / 1970$ & casado & Médio completo & comerciante \\
\hline 6 & Josué de Oliveira Kersten & PT & 2489 & $20 / 08 / 1949$ & divorciado & Superior completo & médico \\
\hline 7 & $\begin{array}{l}\text { Paulo Henrique Areias } \\
\text { Horácio }\end{array}$ & PSDB & 2566 & $25 / 12 / 1965$ & casado & Superior completo & advogado \\
\hline 8 & Pedro Gilmar Nogueira & PTN & 2395 & $11 / 02 / 1960$ & casado & Fundamental completo & motorista particular \\
\hline 9 & Pedro Ferreira de Lima & PMDB & 3180 & $10 / 08 / 1967$ & casado & Médio completo & comerciante \\
\hline 10 & $\begin{array}{l}\text { Vanderlei Francisco de } \\
\text { Oliveira }\end{array}$ & DEM & 2657 & $24 / 05 / 1974$ & casado & Médio completo & $\begin{array}{l}\text { cabeleireiro e } \\
\text { barbeiro }\end{array}$ \\
\hline 11 & Wilson Roberto David Mota & PSD & 2197 & $07 / 09 / 1962$ & casado & Superior completo & agrônomo/advogado \\
\hline & $\begin{array}{l}\text { Alexandre Gotfrid (suplente } \\
\text { que assumiu) }\end{array}$ & PT & 946 & $04 / 11 / 1975$ & casado & Superior completo & professor \\
\hline
\end{tabular}

FONTES: http://www.camaraaraucaria.pr.gov.br/, http://politicaaraucaria e https://apps.tre-pr.jus.br,

http://www.tse.jus.br/eleicoes/eleicoes-anteriores/eleicoes-2012/resultado-da-eleicao-2012. Acesso 29.fev.2016 


\section{AS MULHERES NO PODER LEGISLATIVO DE ARAUCÁRIA}

Somente nas eleições de 2000 temos a escolha da primeira mulher para a Câmara Municipal de Araucária, Marilda Gilinski, que assumiu na 13 ${ }^{\text {a }}$ legislatura (2001-2004). Nessa mesma legislatura a vereadora suplente Rosicler Almeida também assume, já na primeira sessão da câmara em 4 de janeiro de 2001, ficando até o final do mandato. Na legislatura seguinte, a 14 ${ }^{\text {a }}$ (2005-2008), não houve nenhuma vereadora na câmara municipal, apesar de haverem mulheres candidatas e as duas primeiras vereadoras, Marilda e Rosicler, terem se recandidatado, mas não foram reeleitas. Somente na $15^{\mathrm{a}}$ legislatura (2009-2012) uma nova vereadora é eleita, Adriana Cocci, a única na câmara municipal, que se recandidatou para a 16 ${ }^{\text {a }}$ legislatura (2013-2016) e foi reeleita. Hoje, Adriana Cocci é a vereadora na Câmara Municipal de Araucária, entre os 11 vereadores que compõem o legislativo municipal. Foi somente na $15^{\text {a }}$ legislatura a primeira vez que uma mulher compôs a mesa da câmara municipal - Adriana Cocci foi a $2^{\mathrm{a}}$ secretária no $1^{\mathrm{o}}$ biênio (2009-2010). Atualmente, Adriana Cocci é a $1^{\mathrm{a}}$ secretária no $2^{\circ}$ biênio da $16^{\mathrm{a}}$ legislatura.

VEREADORAS DO MUNICÍPIO DE ARAUCÁRIA - PR (1890-2016)

\begin{tabular}{|c|c|c|c|c|c|c|}
\hline NOME & $\begin{array}{l}\text { DATA } \\
\text { NASC. }\end{array}$ & $\begin{array}{c}\text { ESTADO } \\
\text { CIVIL }\end{array}$ & ESCOLARIDADE & PROFISSÃO & $\begin{array}{c}\text { FILIAÇÃO } \\
\text { PARTIDÁRIA }\end{array}$ & MANDATOS \\
\hline $\begin{array}{l}\text { Marilda } \\
\text { Gilinski }\end{array}$ & $20 / 04 / 1958$ & viúva & $\begin{array}{l}\text { Fundamental } \\
\text { incompleto }\end{array}$ & comerciante & PTB & $\begin{array}{l}13^{\mathrm{a}} \text { legislatura } \\
(2001-2004)\end{array}$ \\
\hline $\begin{array}{l}\text { Rosicler } \\
\text { Regina } \\
\text { Almeida } \\
\text { de Souza }\end{array}$ & $14 / 03 / 1964$ & divorciada & Superior completo & professora & PPS & $\begin{array}{c}13^{\mathrm{a}} \text { legislatura } \\
(2001-2004)\end{array}$ \\
\hline $\begin{array}{l}\text { Adriana } \\
\text { Cocci de } \\
\text { Moraes } \\
\text { Castro }\end{array}$ & $30 / 04 / 1972$ & casada & Superior completo & comerciante & PTN & $\begin{array}{c}15^{\mathrm{a}} \text { legislatura } \\
(2009-2012) \\
2^{\mathrm{a}} \text { secretaria (2009- } \\
2010) \\
\\
16^{\mathrm{a}} \text { legislatura } \\
(2013-2016) \\
1^{\mathrm{a}} \text { secretária (2015- } \\
2016)\end{array}$ \\
\hline
\end{tabular}

Elaboração das autoras. Fonte: http://www.tre-pr.jus.br/. Acesso 29.fev.2016 


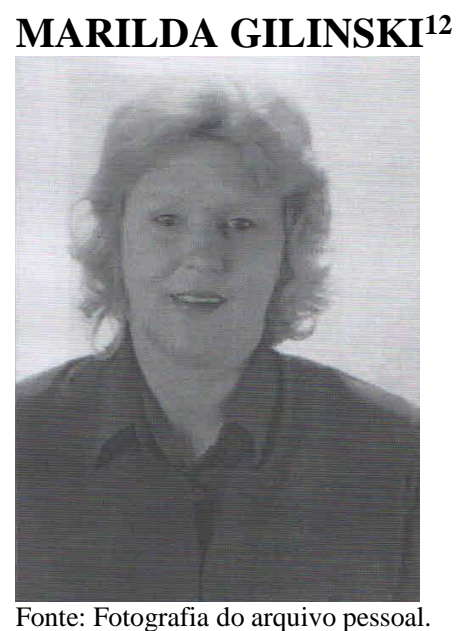

Nasceu em 20 de abril de 1958 em Irati, estado do Paraná. Em 1977, devido ao casamento, mudou-se para Araucária. Possui o Ensino Fundamental incompleto. Ficou viúva aos 23 anos e possui três filhos: Claudia, Ana Maria e Paulo. Revezava-se entre a função de dona de casa e vendedora autônoma. Atualmente exerce a função de administradora rural.

Em 1988 surge como liderança comunitária no Bairro Barigui onde permanece morando até os dias atuais. Torna-se presidente da Associação de Moradores do Bairro Barigui e presidente da Associação de Pais e Mestres/APM da Escola Vitório Sfendrych e organiza sua reconstrução. Em 1989, com a grande demanda de crianças sem creches reinvindica a construção de uma para o bairro e é construída feita a creche Branca de Neve e posteriormente a creche Anjo Azul, e assume a coordenação dessas creches. Devido a sua grande representatividade no Bairro Barigui, em 1999 ajudou a montar o projeto do Portal Polônico que existe na entrada da cidade homenageando os imigrantes poloneses do município. Esse projeto teve apoio de diversas entidades, entre elas da EMATER/Empresa de Assistência Técnica e Extensão Rural.

Inicia sua trajetória política em 1988 quando concorre pela primeira vez ao cargo de vereadora pelo Partido Liberal/PL obtendo o total de 153 votos $^{13}$, mas não foi eleita. Nas eleições municipais de 1992 concorreu ao cargo de vereadora por Araucária pelo Partido Democrata Trabalhista/PDT. Obteve 482 votos e não foi eleita. ${ }^{14}$ Nas eleições municipais de 1996 concorre novamente a cargo de vereadora. Obteve 689 votos e ficou na suplência do PDT. Deixou o PDT por

\footnotetext{
${ }^{12}$ Fotos e dados disponíveis em http://www.quadropolitico.com.br/DadosCandidato/2662182/Marilda-Gilinski. Acesso 29.fev.2016.

13 Disponível em http://www.tre-pr.jus.br/eleicoes/resultados/resultados-de-eleicoes-municipais-tre-pr. file:///C:/Users/User/Downloads/19881115A74357.pdf. Acesso em 29.fev.2016

${ }^{14}$ Disponível em https://apps.tre-pr.jus.br/files/resultados/19921003A74357.pdf. Acesso em 29.fev.2016.
} 
divergências com o presidente do partido $^{15}$. Nas eleições de 2000 consegue se eleger vereadora pelo Partido Trabalhista Brasileiro/PTB com 515 votos. ${ }^{16}$ Foi a primeira mulher eleita para a Câmara Municipal de Araucária.

Nas eleições de 2002 saiu candidata ao cargo de deputada estadual pelo PTB obtendo o total de $1269 \operatorname{votos}^{17}$, mas não foi eleita, ficando na suplência ${ }^{18}$. Nas eleições de 2004 candidatou-se a reeleição como vereadora, pelo PSB. Obteve 333 votos e não foi reeleita ${ }^{19}$.

Durante o período que atuou como vereadora a sua gestão teve como foco educação, adolescentes e crianças ${ }^{20}$. Relata que havia muito preconceito e machismo por ser mulher mas, que depois houve aceitação de seus colegas vereadores. Destaca que em relação a participação das mulheres na política deveria haver mais participação feminina "as mulheres já trabalham muito em sua vida pessoal e são ativas e presentes e se tivessem mais mulheres na câmara seria bem melhor!"21

Deixou a vida política pelo "desencantamento com a própria política pois sentiu resistência de alguns vereadores no período em que atuou na câmara de Araucária em 2001 na sua legislatura". Ressalta que quando realizava seu trabalho como líder comunitária "as portas estavam sempre abertas" para o atendimento da comunidade ${ }^{22}$.

Permaneceu sem se filiar a partidos políticos por 11 anos, e abandonou a carreira política por desilusão "a política é muito bonita como é falada mas, é mudada entre quatro paredes". Atualmente está filiada ao Partido Popular Socialista/PPS por acreditar em "mudanças na sociedade" e não descarta a possibilidade de voltar à vida pública ${ }^{23}$.

\footnotetext{
${ }^{15}$ Conforme entrevista concedida à Adriane Ferrari em abril de 2016.

16 Disponível em http://www.tre-pr.jus.br/eleicoes/resultados/resultados-de-eleicoes-municipais-tre-pr. Acesso em 29.fev.2016

17 Disponível em http://www.tse.jus.br/eleicoes/eleicoes-anteriores/eleicoes-2002/resultado-da-eleicao-2002. Acesso 29.fev.2016

${ }^{18}$ Disponível em http://politicario.com.br/p/busca/?t=2. Acesso em 29.fev.2016

19 Disponível em http://www.tre-pr.jus.br/eleicoes/resultados/resultados-de-eleicoes-municipais-tre-pr. Acesso em 29.fev.2016

${ }^{20}$ Ver Anexo 1 ao final do artigo - Projetos de Lei enviados pela vereadora Marilda Gilinski.

${ }^{21}$ Conforme entrevista concedida à Adriane Ferrari em abril de 2016.

${ }^{22}$ Conforme entrevista concedida à Adriane Ferrari em abril de 2016.

${ }^{23}$ Conforme entrevista concedida à Adriane Ferrari em abril de 2016.
} 


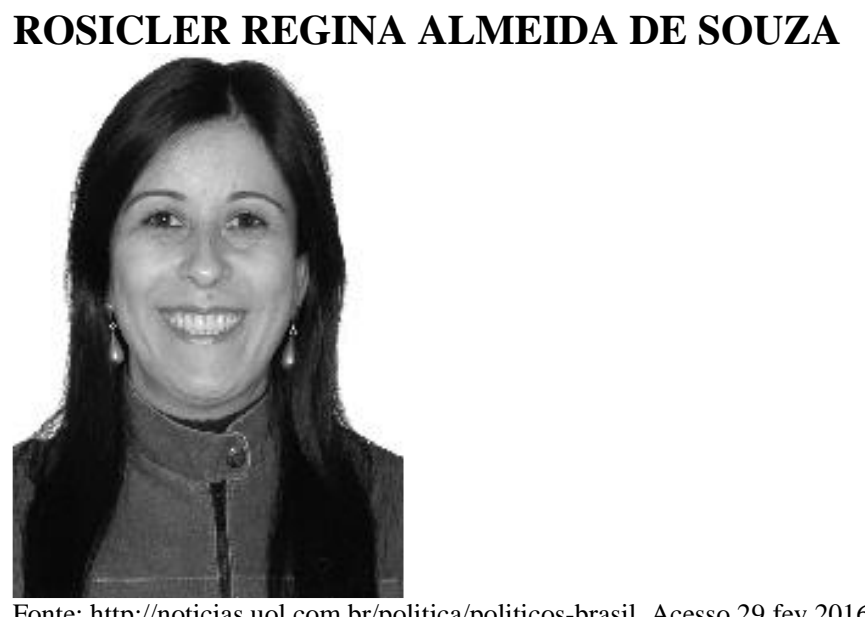

Fonte: http://noticias.uol.com.br/politica/politicos-brasil. Acesso 29.fev.2016

Nasceu em 14 de março de 1964 em Palmeira, estado do Paraná. Chegou ao município de Araucária aos quatro anos de idade com seus pais que migraram por motivos de trabalho. É divorciada e possui dois filhos: Camila e José Carlos. Graduada no curso de Pedagogia, inicia sua carreira no magistério municipal em 1980, atuando como recreacionista. Também foi professora, pedagoga e diretora de escola. Na Escola Municipal Archelau de Almeida Torres foi diretora auxiliar por de dez anos e nesse mesmo período também assumiu a direção geral do Colégio Estadual Professora Helena Wysocki. Nos dez anos que esteve exercendo o cargo de diretora escolar percebeu a necessidade de mudanças na comunidade e a sua vivência na educação trouxe esse impulso para a participação na vida política ${ }^{24}$.

Candidata-se a vereadora em 2000, pelo Partido Democrático Trabalhista/PDT (não aderindo ao sistema de cotas partidárias) já defendendo a necessidade da participação feminina na vida política e pública. Obteve 1236 votos e não foi eleita, mas ficou na suplência, assim assumiu como vereadora suplente na $13^{\text {a }}$ legislatura em 04 de janeiro de 2001, no lugar de Clodoaldo Nepomuceno Pinto Júnior que renunciou para assumir a Secretaria Municipal de Obras Públicas na gestão do prefeito Albanor José Ferreira Gomes. Em sua legislatura teve como foco de trabalho a mulher e a necessidade da construção do seu espaço na sociedade, os adolescentes e a segurança pública $^{25}$.

\footnotetext{
${ }^{24}$ Conforme entrevista concedida para Adriane Ferrari em abril de 2016.

${ }^{25}$ Conforme entrevista concedida para Adriane Ferrari em abril de 2016.
} 
Nas eleições de 2002 registrou candidatura para concorrer ao cargo de deputada estadual pelo Partido Democrático Trabalhista/PDT, mas renunciou à candidatura e não concorreu nas eleições.

Nas eleições de 2004 foi novamente eleita vereadora suplente para a $14^{\text {a }}$ legislatura (20052008). Obteve 678 votos pelo Partido Democrático Trabalhista PDT/12 $2^{26}$, mas dessa vez não chegou a assumir. Concorre nas eleições de 2008 para a 15 $5^{\text {a }}$ legislatura (2009-2012), mas obteve apenas 474 votos não sendo eleita. Nessas eleições concorreu pelo Partido Popular Socialista PPS/23, saindo do PDT $^{27}$ pois, segundo Rosicler “o antigo partido Partido Democrático Trabalhista/PDT não tinha estrutura política”.

Com o fim da sua legislatura como vereadora em 2004 retorna a suas atividades de professora. Entre 2007-2008 foi Secretária de Cultura e Turismo no município de Araucária. No período de 2009-2010 atua como professora. No período de 2011-2012 assume o cargo de Diretora Técnica de Transporte Escolar. No ano de 2013 até março de 2015 assume o cargo de Coordenadora da Biblioteca Municipal Emiliano Perneta.

Em sua trajetória política Rosicler relata que existiram algumas dificuldades iniciais por ser mulher na câmara legislativa. Sentiu em alguns momentos o preconceito por parte de alguns colegas homens. Relata que a importância da participação feminina na política deve acontecer mais efetivamente pois, "a mulher possui uma grande sensibilidade e tem um olhar diferenciado em relação a algumas questões", acredita que "as mulheres podem e devem trabalhar de forma mais organizada possível as políticas públicas para melhorar cada vez mais nossa condição de vida. E isso é algo que interessa não só as mulheres, mas sim a todos os homens que querem viver de igual para igual, com aquelas que junto, e não contra eles, podem construir um mundo mais humano e mais feliz". ${ }^{28}$

Atualmente não está filiada a nenhum partido político e exerce o cargo de Diretora Geral do CEU (Centro de Artes e Esportes Unificados) no município de Araucária.

\footnotetext{
${ }^{26}$ Disponível em http://www.quadropolitico.com.br/DadosCandidato/2108506/Rosicler-Regina-Almeida. Acesso em 29.fev.2016.

27 Fotos e dados disponíveis em http://noticias.uol.com.br/politica/politicos-brasil/2008/vereador/17011953-jorgezimmermann.jhtm. Acesso 29.fev.2016.

${ }^{28}$ Conforme entrevista concedida para Adriane Ferrari em abril de 2016.
} 


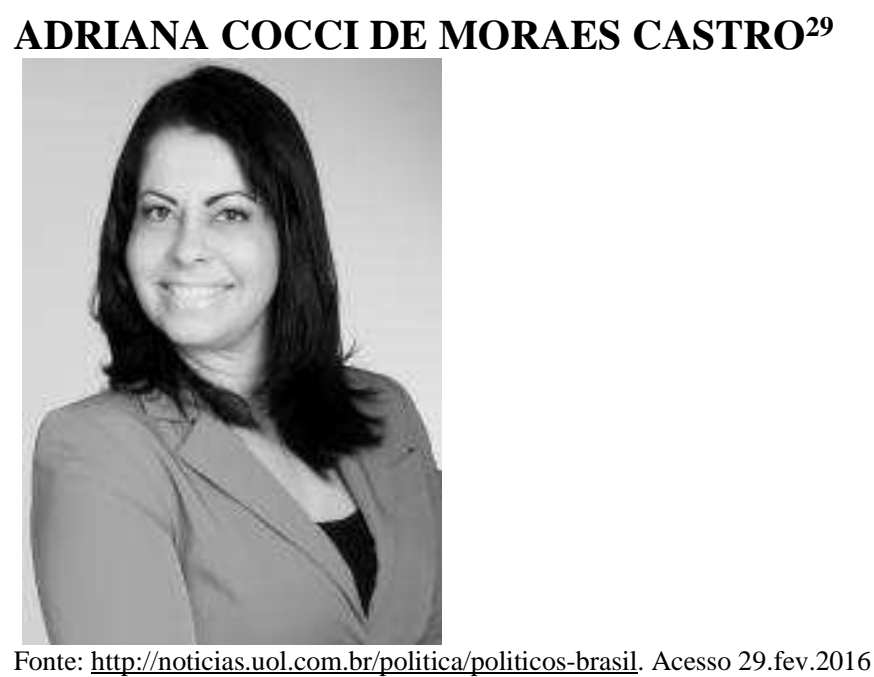

Nasceu em 30 de abril de 1972 em Cianorte, estado do Paraná. Chega a Araucária aos 17 anos com seus pais. É casada com Adriano de Castro e tem dois filhos: Vinícius e Gabriel. Antes de ser vereadora era comerciante. Seu interesse pela participação na vida política surge quando participou da campanha do candidato a vereador Dr Araré Gonçalves Cordeiro Júnior, em 1996, pelo Partido Trabalhista Brasileiro $/ \mathrm{PTB}^{30}$. A partir de então passou a ter como desejo pessoal participar da vida política do município ${ }^{31}$.

Candidata-se nas eleições municipais de 2000, pelo Partido Trabalhista Brasileiro/PTB para o cargo de vereadora. Obteve 459 votos e ficou como suplente ${ }^{32}$. Nas eleições de 2004 deixa o Partido Trabalhista Brasileiro/ PTB e entra no Partido da República/PR pois "acreditava que o novo partido trazia a perspectiva de militância e conscientização, e através da mudança de pensamento, muda-se o comportamento" 33 . Nessas eleições obteve 998 votos e ficou novamente no cargo de

\footnotetext{
${ }^{29}$ Disponível em http://www.eleicoes2014.com.br/adrina-cocci-de-moraes-castro/. Acesso em 29.fev.2016.

${ }^{30}$ Nas eleições municipais de 1996, Araré Gonçalves Cordeiro Júnior obteve 704 votos nominais e ficou como suplente. Disponível em https://apps.tre-pr.jus.br/files/resultados/19961003A74357.pdf. Acesso 30.abril.2016.

${ }^{31}$ Conforme entrevista concedida à Adriane Ferrari em abril de 2016.

${ }^{32}$ Disponível em http://www.tse.jus.br/eleicoes/eleicoes-anteriores/eleicoes-2000/resultado-da-eleicao-2000. Acesso em 30.março. 2016

${ }^{33}$ Conforme entrevista concedida à Adriane Ferrari em abril de 2016.
} 
suplente $^{34}$. Chegou a ser convocada para assumir como vereadora suplente, mas, optou por não exercer a função porque "não teria liberdade para trabalhar"35.

Entre 2005 a 2008 assume, por um ano e meio, o cargo de diretora geral da Secretaria Municipal de Comunicação Social e logo após nesse mesmo período assume a coordenadoria do Centro de Convivência de $\operatorname{Idosos}^{36}$.

Nas eleições de 2008 foi eleita, pelo Partido Trabalhista Nacional/PTN, como vereadora com um total de 2409 votos, assumindo na 15 a legislatura (2009-2012). Em 2012 é reeleita vereadora, com um total de 2196 votos para a $16^{\text {a }}$ legislatura $(2013-2016)^{37}$.

Em 2014 foi candidata a Deputada Estadual do Paraná pelo Partido Trabalhista Nacional/PTN, obteve 8.081 votos $(0.14 \%)$ mas não foi eleita devido ao quociente partidário e a legenda do seu partido.

No período da primeira legislatura e na atual tem como foco de atuação o trabalho a promoção social como um todo, mas, suas maiores "preocupações" são idosos e mulheres ${ }^{38}$. Com relação as mulheres, a vereadora destaca a fragilidade das políticas públicas voltadas as elas e o alto índice de violência praticada contra elas, por isso procura "apresentar e participar constantemente de projetos que visem a valorização das mulheres" 39 . Paralelo ao legislativo, busca parcerias junto à comunidade e empresas, como o projeto "Levando o bem "que tem como objetivo o acolhimento aos pais de dependentes químicos durante o seu processo de tratamento. Esse projeto tem como parceiros a Associação Esportiva do bairro Califórnia e a empresa Petrobrás ${ }^{40}$.

No início da sua trajetória política, em sua primeira campanha no ano de 2000 sentiu que o preconceito muitas vezes vinha das próprias mulheres que diziam: "que política não era coisa de mulher". Ao começar a sua primeira legislatura em 2009, observa que alguns vereadores "olham

\footnotetext{
${ }^{34}$ Disponível em http://www.quadropolitico.com.br/DadosCandidato/2108506/. Acesso em 29.fev.2016.

${ }^{35}$ Conforme entrevista concedida à Adriane Ferrari em abril de 2016.

${ }^{36}$ Conforme entrevista concedida à Adriane Ferrari em abril de 2016.

${ }^{37}$ Disponível em http://www.quadropolitico.com.br/DadosCandidato/2108506/. Acesso em 29.fev.2016.

${ }^{38}$ Conforme entrevista concedida à Adriane Ferrari em abril de 2016.

${ }^{39}$ Ver anexo ao final do artigo Projetos de Lei Enviados pela vereadora Adriana Cocci.

${ }^{40}$ Conforme entrevista concedida à Adriane Ferrari em abril de 2016.
} 
com estranheza a presença feminina”, mas ressalta que sempre houve o respeito e a consideração de $\operatorname{todos}^{41}$.

Acredita que deve haver respeito entre homens e mulheres para uma vida melhor e conclui "que a política tem como papel buscar caminhos para que homens e mulheres possam andar lado a lado respeitando suas diferenças e buscando um caminho único de uma vida melhor para todos".

\section{CONSIDERAÇÕES FINAIS}

Baixa representatividade feminina - assim é caracterizada a Câmara Municipal de Araucária, pois ao longo de sua história, que começa em 1890, somente 3 mulheres foram eleitas vereadoras e atualmente a CMA (Câmara Municipal de Araucária) conta com apenas uma vereadora.

Sendo as mulheres $52 \%$ dos eleitores brasileiros, tendo conquistado avanços em relação aos seus direitos, a representação política ainda é muito pequena. Esse é um tema que precisa se estudar muito, saber por que, qual a responsabilidade, inclusive dos partidos políticos nessa baixa representatividade. $\mathrm{O}$ fato de se ter uma única representante feminina na câmara municipal reflete a falta de apoio dos partidos políticos às mulheres que ingressam na política e que o "machismo" é um dos principais fatores predominantes nessa falta de apoio? Vemos que tem aumentado a participação da mulher na política e elas têm interesse na questão, mas o problema parece ser ainda a falta o apoio. De acordo com o Tribunal Superior Eleitoral, dos 157 candidatos a vereador no município de Araucária nas eleições de 2012, 51 eram mulheres, mas somente uma foi eleita, conforme quadro a seguir.

Cabe ressaltar que esse é um estudo introdutório, pois foi realizado apenas uma primeira sistematização de dados, uma vez que nenhum estudo anterior com esse tema foi realizado sobre o município de Araucária. Ainda há muitos dados a serem levantados e analisados como as comissões nas quais cada vereadora participou, seus votos nos projetos apresentados na CMA durante suas respectivas legislaturas, a natureza dos projetos propostos e votados (aprovações ou não) por elas, as mudanças ou não de partidos políticos, analisar os anais da CMA para levantar os discursos dessas vereadoras e suas perspectivas e capacidade de articulação dentro do "jogo político", suas

\footnotetext{
${ }^{41}$ Conforme entrevista concedida à Adriane Ferrari em abril de 2016.
} 
tomadas de posição enquanto governismo/situacionismo e oposicionismo, além das possíveis redes e conexões de parentesco que as possam ter levado ao ingresso no mundo da política.

Além dos estudos das características de atuação de cada vereadora e de seus dados biográficos que devem ser melhor estudados e aprofundados, cabe ainda uma análise mais ampla, de caráter institucional que considere a seleção dos indivíduos realizados pelos partidos políticos até o lançamento das candidaturas para melhor poder analisar a participação das mulheres na Câmara Municipal de Araucária à luz da política de cotas de gênero ${ }^{42}$. A política de cotas de gênero é controversa, já que os partidos que não apresentam o percentual exigido não sofrem nenhum tipo de punição e, a lei se refere apenas às candidaturas, podendo não refletir efetivamente em representação política. Por outro lado, a lei traz para o debate a necessidade de inclusão de diversos grupos na arena política nacional (Leal, 2014).

Candidatos à Câmara Municipal de Araucária - PR/Eleições 2012

\begin{tabular}{|c|c|c|c|c|}
\hline $\begin{array}{c}\text { PARTIDO } \\
\text { POLÍTICO }\end{array}$ & $\begin{array}{c}\text { TOTAL DE } \\
\text { CANDIDATOS }\end{array}$ & CANDIDATAS & NOME CANDIDATA & $\begin{array}{c}\text { TOTAL DE } \\
\text { VOTOS }\end{array}$ \\
\hline PRB & 1 & zero & & 83 \\
\hline PP & 3 & 1 & Josi Amaral & 48 \\
\hline PDT & 12 & 6 & Adriane Pereira & 161 \\
\hline & & & Andreia da Saúde & 24 \\
\hline & & & Clarice A Pintora & Mari \\
\hline & & & Vivi & 49 \\
\hline & & & Zuleide dos Santos & 86 \\
\hline PT & & & Fabiane Alves & 50 \\
\hline & & 2 & Cátia Regina & 4 \\
\hline PTB & 9 & 3 & Dirce Matioli & 156 \\
\hline & & & Giona & 1 \\
\hline & & & Tia Nana & 49 \\
\hline PMDB & 10 & 5 & Andrea & 225 \\
\hline & & & Dra. Sandra Viana & 384 \\
\hline & & & Irene & 82 \\
\hline & & & Line Povão & 41 \\
\hline & & & Sirley Castanho & 1 \\
\hline PSL & 6 & 1 & Adriana Wagner & 2196 \\
\hline
\end{tabular}

${ }^{42} \mathrm{O}$ artigo $10, \S^{\circ}$ da Lei $n^{\circ} 9.504 / 1997$ obriga partidos e coligações a preencher no mínimo $30 \%$ das vagas indicadas para as eleições proporcionais com candidatas em atendimento à ação afirmativa que busca dar maior espaço às mulheres na política. É uma importante ferramenta de incentivo à participação política das mulheres, historicamente afastadas dos pleitos eleitorais. 


\begin{tabular}{|c|c|c|c|c|}
\hline & & & Maria do Condor & 55 \\
\hline PSC & 7 & 1 & Negaton & 70 \\
\hline PR & 2 & 1 & Tia Maria & 54 \\
\hline \multirow[t]{6}{*}{ PPS } & 18 & 6 & Adimar Souza & 58 \\
\hline & & & Monica Coser & 491 \\
\hline & & & Monica Paço & 110 \\
\hline & & & Professora Rita & 84 \\
\hline & & & Shirley & 76 \\
\hline & & & Vera da Academia & 165 \\
\hline DEM & 6 & 1 & Carla Ribeiro & 146 \\
\hline PSDC & 2 & zero & & \\
\hline PRTB & 1 & zero & & \\
\hline \multirow[t]{2}{*}{ PHS } & 7 & 2 & Barbara Bossi & 160 \\
\hline & & & Sara Locações & 101 \\
\hline \multirow[t]{2}{*}{ PTC } & 10 & 2 & Dra Elisa & 153 \\
\hline & & & Luciana Queiroz & 22 \\
\hline \multirow[t]{3}{*}{ PSB } & 8 & 3 & Ana Paula & 109 \\
\hline & & & Cinthia Paitra & 33 \\
\hline & & & Ione da Tupi & 159 \\
\hline \multirow[t]{5}{*}{$\mathrm{PV}$} & 16 & 5 & Elisandra & 115 \\
\hline & & & Ilene Cristo & 285 \\
\hline & & & Professora Mara & 153 \\
\hline & & & Salete Severino & 123 \\
\hline & & & Tati Soczek & 62 \\
\hline \multirow[t]{5}{*}{ PRP } & 11 & 5 & Alien Borges & 1 \\
\hline & & & Any da Van & 89 \\
\hline & & & Eva Coller & 98 \\
\hline & & & Professora Cirene & 95 \\
\hline & & & Professora Marili & 221 \\
\hline \multirow[t]{4}{*}{ PSDB } & 13 & 4 & Elda Tuleski & 868 \\
\hline & & & Luciani & 3 \\
\hline & & & Luiza & 33 \\
\hline & & & Tati & 8 \\
\hline PPL & 2 & 1 & Renata Almeida & 28 \\
\hline PSD & 2 & zero & & \\
\hline PC do B & 1 & zero & & \\
\hline
\end{tabular}

Elaboração das autoras. Fonte: http://www.tre-pr.jus.br/.. Acesso 29.fev.2016

\section{REFERÊNCIAS}

BARBOSA, Fernanda Leal (2014). As cotas eleitorais de gênero como um instrumento de ação afirmativa eleitoral. Revista Âmbito Jurídico, 01/03/2014, No 122 - Ano XVII. Disponível em http://www.ambitojuridico.com.br/site/index.php?n_link=revista_artigos_leitura\&artigo_id=14536 \&revista_caderno=28. Acesso em 29.fev.2016.

KERSTEN, Márcia Scholz de Andrade (1983) O colono-polaco: a recriação do camponês sob o capital. Dissertação de mestrado em História Econômica do Brasil. Curitiba: UFPR.

OLIVEIRA, Dennison de (2001). Urbanização e industrialização no Paraná. Coleção História do Paraná - textos introdutórios. Curitiba: SEED. 
WACHOWICZ, Ruy Christovam (1988). História do Paraná. Curitiba: Editora Gráfica Vicentina Ltda.

WACHOWICZ, Ruy Christovam (1977). Tomás Coelho: uma comunidade camponesa. Araucária: Prefeitura Municipal de Araucária.

Coleção Histórica de Araucária - Museu Tingüi-Cuera Vol. 1. Agricultura e Indústria - A Memória do Trabalho em Araucária - 1990 


\section{ANEXO - Projetos de Lei Enviados pela vereadora Adriana Cocci}

2009

PL No8/2009 - Reserva de vagas a negros e pardos em concursos públicos. (16.02.09) - Lei $\mathrm{N}^{\circ}$ 2.070/2009

PL No010/2009 - Institui no município de Araucária a Semana de Prevenção a Saúde do Servidor Público Municipal. (05.03.09) - Lei No 2.040/2009

PL No011/2009 - Criação do Programa de recolhimento de pilhas e baterias usadas no município. (09.03.09) - Lei $N^{\circ} 2.064 / 2009$

PL N037/2009 - Cria no município de Araucária o "Programa de Bibliotecas Públicas nos Bairros". (13.05.09) - Lei No 2.2001/2010

PL No039/2009 - Atendimento preferencial aos doadores de sangue em estabelecimentos comerciais, bancários, de serviços e similares, eventos culturais e nas repartições públicas em Araucária. (14.05.09)

PL Nº44/2009 - Veda o assédio moral no âmbito da administração pública municipal direta ou indireta. (25.05.09)

PL N045/2009 - Lei que dispõe sobre a obrigatoriedade da rede de supermercados sediados no município de Araucária, a disponibilizar assentos para os operadores de caixa. (25.05.09) Lei $N^{\circ} 2.132 / 2009$

PL N091/2009 - Implantação de mecanismos de proteção nas agências bancárias sediadas no município de Araucária. (28.08.09) - Lei No 2.072/2009

PL N093/2009 - Implantação do Programa Justiça Comunitária Itinerante no Município de Araucária. (08.09.2009) - Lei No 2.130/2009

PL No094/2009 - Autorização ao Poder Público para celebração de convênios com a Itaipu Binacional e com a Indústria Siderúrgica Guairá S/A para o fim que especifica. (08.09.2009) Lei $N^{\circ} 2.116 / 2009$

PL No095/2009 - Criação de cabinas nos pontos de táxi equipadas com banheiro, sala de espera e telefone público. (08.09.2009) - Lei $\mathrm{N}^{\circ} 2.185 / 2010$

PL No096/2009 - Implantação do Programa Vida nos Bairros, com o objetivo de oferecer atividades esportivas, recreacionais, culturais e de lazer. (08.09.2009) - Lei $\mathrm{N}^{\circ} 2.131 / 2009$

PL No097/2009 - Implantação do Barracão Cultural da Cidadania, o programa consiste em difundir a arte e cultura nos bairros. (08.09.2009) - Lei $N^{\circ} 2.188 / 2010$

PL N099/2009 - Criação da Casa de Passagem em favor das vítimas de violência doméstica. (10.09.2009) - Lei $N^{\circ} 2.183 / 2010$ 
PL N¹00/2009 - Projeto de criação do Programa de Subsídio Educacional, suporte financeiro ao estudante durante o período que estiver cursando o $3^{\circ}$ grau ou curso. (15.09.2009)

PL N $\mathbf{N}^{\mathbf{1} 14} / 2009$ - Identificação civil dos estudantes matriculados na rede pública municipal de ensino. (22.10.2009) - Lei $N^{\circ} 2181 / 2010$

2010

PL No24/2010 - Cria o Programa Municipal de Capacitação para profissionais de nível superior, técnico e auxiliar da saúde destinado ao aprimoramento na detecção de diagnóstico de maus tratos sofridos por menores. (23.03.2010)

PL No28/2010 - Disponibilizar no site da prefeitura lista de pessoas desaparecidas na cidade de Araucária. (19.04.2010) - Lei No 2.218/2010

PL No029/2010 - Institui o Dia Municipal de Conscientização e Combate aos Maus Tratos à Pessoa Idosa. (19.04.2010) - Lei No 2.219/2010

PL No030/2010 - Denomina Romeu Poly espaço público do Município de Araucária. (20.04.2010) - Lei $N^{\circ} 2.216 / 2010$

PL Nº75/2010 - Autoriza a criação da Guarda Mirim Municipal. (28.06.2010)

PL Nº82/2010 - Institui o Prêmio Profissionais da Educação. (09.07.2010)

PL Nº92/2010 - Institui o Plano Municipal de Combate à Pedofilia. (04.08.2010) - Lei n'2262/2010.

PL N093/2010 - Implantação de Programa Móvel e Itinerante de Coleta de Sangue e Cadastramento de Doadores de Órgãos e Medula. (05.08.2010).

PL N098/2010 - Criação da Olimpíada da Melhor Idade. (12.08.2010) - 2270/2010.

PL N¹04/2010 - Institui o Dia Municipal do Agente Comunitário de Saúde e do Agente de Combate a Endemias. - Lei N²291/2010.

2011

PL N44.2011 - Dispensa de servidora pública municipal responsável por pessoa excepcional de parte da jornada de trabalho

PL N62.2011 - Garante atendimento prioritário a gestantes de alto risco.

2012

PL 011.2012 - Inclusão de medidas de conscientização, prevenção e combate ao bullying escolar. 
PL 012.2012 - Dia Municipal de luto e reflexão sobre o Holocausto.

PL 018.2012 - Institui a Semana da Família.

2013

PL 014/2013 -Dispõe sobre o programa de troca de óleo usado de cozinha por sabão vegetal no município de Araucária.

\section{4}

PL 06.2014 - Programa Municipal de Capacitação para profissionais de nível superior, técnico e auxiliar da área da saúde destinado ao aprimoramento na detecção de diagnóstico de maus tratos sofridos por menores.

PL 07.2014 - Isenção do pagamento da tarifa do Estacionamento Rotativo para idosos e portadores de deficiência.

PL 021.2014 - Veda o assédio moral no âmbito da administração pública municipal direta e indireta.

2015

PL 015/2015 - Dia Municipal de Conscientização da Adrenoleucodistrofia.

PL 2015 - Institui no calendário oficial do Município de Araucária o "Março Laranja", mês de prevenção e combate ao bullying escolar.

PL 2015 - Dispõe sobre a isenção de imposto sobre a propriedade predial e territorial urbana para pessoas nas condições que especifica.

2016

PL 2016 - Dispõe sobre a isenção do pagamento de tarifas de transporte coletivo as gestantes de alto risco.

PL 2016 - Institui a Política Municipal de Apoio à Agricultura Urbana. 


\title{
LEGISLATIVE POWER AND WOMEN IN ARAUCÁRIA
}

\section{(1890-2016)}

\begin{abstract}
This article aims to analyze the political participation of women in the Municipality of Araucaria, the metropolitan region of Curitiba / PR between the years 1890 to 2016. For this purpose, a database of candidates elected was built and, with it, Could provide a record of women's participation in municipal elections, analyze the profile of councilors from social and economic dimensions, such as age, marital status, education, occupation and political affiliation. The results mark a very low female participation compared to the male presence. Despite certain openness and incentive for greater participation of women in political party life, as established by the quota law, this share falls far short of their populations, as shown by the data on women's participation in local legislative power Araucaria.
\end{abstract}

Key-words: Women in politics. Policy and gender. Hall Araucaria. 